\title{
Operation Oryx: the Three Stages of Captive Breeding
}

\author{
By Ian. R. Grimwood
}

In 1961 the Arabian oryx was in such danger that the only hope for its survival seemed to lie in capturing sufficient animals to start a breeding herd in captivity from which eventually some could be returned to the wild. The Fauna Preservation Society, aided by the World Wildlife Fund, organised Operation Oryx, and under the leadership of Major Grimwood, then Chief Game Warden in Kenya, three animals were captured. These, together with some from the very few in captivity, were sent to Phoenix Zoo in Arizona for stage two of the operation, the breeding of a stock, which is now going on successfully. Stage three, the return to the wild, still lies ahead. Describing the capture expedition, Major Grimwood emphasises the immense interest it aroused, which brought help from six governments, five zoos, scores of societies and clubs, hundreds of individuals, and several oil and other companies, including an electricity company in Kenya which emptied its showroom of ovens in order to heat the oryx's quarantine quarters to save them from the cold.

THERE are many possible approaches to the saving of an en1 dangered animal species threatened with extinction. Undoubtedly the best chance of success is to create an effective reserve around a surviving population in the wild. Where that is not possible alternative solutions may be to transfer a population to a reserve within the former range of the species, or even to one outside its natural range where similar ecological conditions exist, as is being done in the case of the aye-aye in Madagascar; or it may be impossible to do more than control the hunting or capturing of the animal concerned. In these cases a simultaneous captive breeding programme may prove to be a valuable insurance against failure. Nevertheless, the risks and difficulties involved are usually so great, not only in the capturing and handling of an animal whose reaction to shock and stress may be quite unknown, but also in producing artificial conditions which will induce it to breed freely in captivity, that the occasions which justify putting all our eggs in the captive breeding basket will be very few.

In 1961, however, the Arabian oryx, Oryx leucoryx, presented just such a case, and the purpose of this paper is to describe the steps taken in the initial stage of the captive breeding programme, that of getting together a breeding nucleus, and to outline some of the difficulties still to be overcome in the second and third stages, those of building up a numerous and healthy population in captivity and the 
eventual re-introduction of the species into the wild, without which no such programme can be considered a success.

Effect of the Motor Car

The Arabian oryx was formerly plentiful in suitable localities throughout the Arabian peninsula, from Sinai and the Syrian desert in the north to the Arabian sea in the south. Because of its extreme wariness and the great distances it is able to travel-individuals may wander as much as 50 to 60 miles a day in their normal search for food-the species was able to withstand the steady hunting of poorly armed Bedouin operating on foot or with camels, and so difficult was it to kill an oryx under those conditions that it became a distinction to be a successful oryx hunter, even though a man might kill no more than one or two in his whole lifetime. Unfortunately, the distinction persisted after the motor car had removed all the difficulties, making it possible to kill a dozen animals in a day by running them down and slaughtering them as they stood exhausted and helpless. As a result, the species rapidly disappeared from most of its range, exterminated by the rich car-owning class of Arab rather than the Bedouin, although the European employees of oil companies were not guiltless. By 1960 it was thought still to exist only in one area, along the southern, and possibly the eastern edges of the Rub-al-Khali, the great sea of sand dunes in the south-east corner of the Arabian peninsula.

Nothing was known about the eastern part of this region, which lies in the sultanate of Muscat and Oman, other than that Bedouin, coming from Mugshin and Jiddat-al-Harrasis, reported occasionally seeing oryx there. In the western part, which lies in the eastern Aden Protectorate, small parties of from five to ten animals each, totalling perhaps 80 to 100 in all, were in the habit of coming out from the safety of the sand sea each summer, when heat made life insupportable amongst the dunes, and scattering over the gravel plains to the south.

The Spur to Action

Early in 1961, that region was raided by a motorised hunting party from Qatar, over 500 miles to the north, which killed at least 48 oryx-approximately half the known population of the species. For this party to have crossed the Rub-al-Khali was a remarkable feat in itself, but having done so once it could obviously do it again. The Fauna Preservation Society, in conjunction with the Survival Service Commission of IUCN, realising that immediate action was necessary, decided to send an expedition to capture a breeding nucleus while some animals still survived. I, who was then Chief Game Warden of Kenya, was asked to take charge of the operation in the field.

We planned our attempt for the following April or May, at which time of year we thought the oryx would be sure to have come out of the dunes on to the plains where they could be caught, but when temperatures should not be so high as to endanger them during capture. In February, however, we received news that the raiders 
had returned, and they were reported to have killed all the surviving oryx. Despite this blow to its hopes, the Fauna Preservation Society decided that the expedition should continue as planned, in the hope that some animals had survived the hunters. So in March we moved to Mukalla, and a month later reached Sanau, the last outpost of the Hadhrami Bedouin Legion and the nearest water to the area in which we were to operate.

\section{The Hunt in the Desert}

The region where oryx might be found was a rough quadrilateral of some 8000 square miles of sand and gravel plains with its northern side running for 100 miles along the edge of the sand sea. Although tracks of the ten vehicles used by the raiders were to be seen everywhere, we could at first find no recent signs of oryx. After a week, however, we came across the spoor of one animal, and having followed it for two days sighted and caught our first oryx. By the time the expedition was over and we had explored the whole area thoroughly, we came to the conclusion that no more than eleven animals had survived the raid, of which five had left the area before our arrival and travelled so far east into the neighbouring state of Oman that it was politically impossible for us to follow them. Four others, three males and one female, we tracked down and caught, killing one of the males in the process, while the other two, which we never saw, alarmed either by our spotter aircraft or the vehicles, escaped into the sand sea, where we could not go, and from which they did not emerge again while we were in the area.

The surviving two males and one female of the four we caught were flown to Kenya, from where, after being held for a period of some months in specially prepared quarters at Isiolo, in the northern sub-desert zone, they were flown to Clifton quarantine station at New York, and finally on to the Arizona Zoological Society's zoo at Phoenix. On the way they were joined in London by a young female from the London Zoo, which the London Zoological Society had put into the common pool.

\section{The Hunt in the Zoos}

The two pairs thus completed could by no means be considered a viable breeding nucleus, and we of the field party were very conscious of our failure to realise the hopes of the Society, so an intensive search started for other oryx already in captivity which might be added to the "world herd" as it had begun to be called. All animals reported to be held by various zoos turned out to belong to other species, however, or to be hybrids like the scimitar-horned oryx-addax, crosses in the Rome Zoo, and it became apparent that the female from the London Zoo had been the only Arabian oryx in captivity, either in Europe or America. (The London Zoo also possessed a male, but it was semi-crippled and unfit for breeding purposes.)

However, two animals of unknown sex and in pretty poor condition were located wandering, apparently ownerless, in the suks of Taiz, 
capital of Yemen. It was also learned that HH Sheikh Jaber Abdullah al Sabah, the then ruler of Kuwait, possessed two females in his private zoo, and that HM King Saud bin Abdul Aziz of Saudi Arabia had a private collection of at least eight oryx, about which little could be discovered, except that when last reported on they had not been in the best of condition and were nearly all males. Britain was not at that time on speaking terms with the Yemen, but the US Chargé d'Affaires undertook to negotiate for the acquisition of the Taiz animals. He had finally to report failure, however, in the face of strong municipal opposition, so hope of adding them to the world herd had to be abandoned.

In contrast, Sheikh Abdullah, when the position was explained to him, showed great interest in the attempt to save the species and at once offered both his animals to the Fauna Preservation Society. Unfortunately, before they could be collected one died in delivering a calf sired by a beisa oryx, but the other, which had survived the birth of a similar calf, was flown to Mombasa for quarantining and subsequently joined the others at Phoenix in September, 1963.

The Herd at Riyadh

King Saud proved more difficult to contact but eventually a reply was received to one of the many approaches which had been made that His Majesty would be pleased to present two pairs of oryx to the World Wildlife Fund, for addition to the world herd. The transfer of those animals to Phoenix presented considerable problems and it was not until March 1964 that I was able to go to Riyadh to collect them. I found then that the oryx were no longer kept at the old palace but had been transferred to a new zoo built in the city, under the control of HH Prince Fahd al Feisal, where there were altogether thirteen beasts, eight males and five females, all in good condition, of which several had been born in captivity. Even after the removal of the four animals for Phoenix a stock of six males and three females remained, which could play an important part if anything should happen to the herd at Phoenix. These last additions to the world herd were quarantined at Naples and after the usual thirty days at Clifton arrived at Phoenix in July 1964.

Thus after two years the relative failure of the capture attempt was partly compensated for by the world herd being brought up to five females and four males-a still barely viable number and one far below the target that we had set ourselves.

Two points emerge from this first stage of the rescue programme. The first is how lucky we were in the species we had to deal with, particularly in regard to the capture of the wild specimens. Not only did the Arabian oryx prove extraordinarily easy to catch, running slowly and straight so that they could be noosed after only a very short chase, and attacking the catching car in only a half-hearted manner so that the risk of damage was slight, but once caught they 
proved to be an extraordinarily docile species, unlike any other I havo encountered. None of our animals attempted to fight its crate, nor did they try to escape from the holding pens which is how so many animals damage themselves; neither did any show timidity or violent panic or alarm. From the start they appeared to be resigned to their fate; and apart from some initial difficulty in getting them to feed their handling proved easy in every way. They also showed remarkably robust constitutions, which was fortunate, because despite the most careful planning we had to subject them to stresses which few other animals could have survived. Instead of the maximum journey of two hours between place of capture and holding pens which trappers are permitted in Kenya, two of our animals had to undergo journeys of over 13 hours immediately after capture, and instead of a minimum period of three weeks in the holding pens the last caught had only been there for five days before all were flown out. They also proved able to withstand rapid changes of climate and temperature, and were only slightly distressed when the aircraft fiying them to Aden had to rise to 10,000 feet over the mountains.

I have already mentioned that one oryx was killed in the process of being caught, but that should not be taken to show a lack of robustness in the species. It was a young animal, already weakened by a bullet wound in one haunch, and we came across it during the heat of the day on ground so broken as to render rapid manoeuvring impossible. Normally, it would have been left alone, but the extraordinary circumstances seemed to justify the taking of almost any risk. In the end, however, the chase lasted 20 minutes, and the animal died of a ruptured liver an hour after being caught.

\section{Help from Every Quarter}

The second point which emerges from this first stage is the extraordinary amount of interest and help which is forthcoming once an enterprise of this sort has been started. Once the Air Ministry in London had given permission for the Royal Air Force to assist, on condition that no non-routine flying was to be involved, the various officers concerned vied with each other in bending service commitments to fit the needs of the operation. Four members of the field team, together with their catching car, light aircraft and other equipment, were flown to Aden from Kenya, while another member was flown out from England. At the end of the expedition a carefully timed ration drop to a Hadhrami Bedouin Legion fort enabled a transport plane to land in the desert and fly the oryx straight to Aden, otherwise a ten-day journey by land. A troop transport plane which had deliberately delayed at Aden then took them on to Nairobi, so that the whole journey from the desert took less than thirteen hours. Later, when the US Department of Agriculture agreed to accept the quarters where the oryx had been held in Isiolo as a quarantine station, provided that the move from there was done by air, the Air Commodore commanding in Kenya himself undertook a training flight in order to 
transport them to the nearest commercial aerodrome. It was also the RAF that later brought Sheikh Abdullah's female oryx from Kuwait to Nairobi.

Equally invaluable was the aid of the Hadhrami Bedouin Legion, which transported the whole expedition from the coast to the area of operations, a week's drive inland, and besides providing the necessary vehicles for keeping the party in the field lent it a signal section for communication with the outside world and half a platoon for local protection. It is no exaggeration to say that the expedition would have been impossible without the help given by Colonel Gray, the Commanding Officer of the Legion. It is especially sad to record that he was ambushed and killed a few weeks ago and his wife seriously wounded.

Support in Kenya was also strong, the Government lending its game biologist to the expedition and supplying African animals for a return present to the Riyadh Zoo, as well as affording certain other facilities. The East African Wildlife Society lent its light aircraft, and Mr. John Seago, a well known animal dealer, allowed Kenya members of the party to use his equipment and vehicles with which to gain experience by catching the much larger beisa oryx. The same dealer also built emergency accommodation for the oryx on their arrival in Nairobi, when onward movement to Isiolo was held up by an outbreak of foot-and-mouth disease, and the local electricity company ran a line to those quarters and rigged them out with all the electric ovens from its show room to save the animals from the cold. On the financial side many people sent contributions to the Fauna Preservation Society to help pay for the expedition, and the remaining costs were covered by a grant from the World Wildlife Fund. When the time came to choose the site of the breeding establishment, the Zoological Society of Arizona offered the facilities of its zoo at Phoenix, where climatic conditions approximate those in Arabia, and where a herd could be built up under fairly free-ranging conditions; and the Shikar-Safari Club of Los Angeles, which had previously contributed generously to game rescue operations in East Africa, came forward to pay the cost of flying the first five animals to New York. Transport costs from Riyadh for the last four animals were shared between the same club and the US National Appeal of the World Wildlife Fund, and the animals were quarantined at the expense of Dr. Cuneo, the Director of the Naples Zoo, who also installed special heating for their comfort. Arrangements for a special charter to collect the oryx from Riyadh, where foreign aircraft are not normally permitted to land, were made by PAN AM, and when difficulties arose at the time of collection the company sent its Arabic-speaking representative from Doha to iron them out. ARAMCO also played a prominent part in the collection of these animals, of which the construction of crates and the provision of local transport were only a small part. Finally, all nine oryx were flown from New York to Phoenix by the Arizona Air National Guard. 
Thus, six governments, five zoos, a score of societies, clubs and major commercial organisations, and hundreds of private individuals in Arabia, Africa, Europe and America took a direct part in the first stage of the effort to re-establish the Arabian oryx. And for that, if no other reason, the resulting breeding nucleus deserves the title of the "world herd."

If enthusiasm of that sort is to be maintained and similar help is to be available for other rescue operations that may become necessary, there is an obvious need for an authority of world standing, not only to decide in each case the method or methods to be used in attempting to save an endangered species, but also to harness all efforts to the agreed plan and to ensure that no available help is wasted. This is the role now filled by the Survival Service Commission of IUCN.

When captive breeding is to be one of the methods adopted there is an equally obvious need for a strong international organisation governing zoos and animal dealers, to ensure that knowledge and resources are pooled, and that all individual interests are subordinated to the welfare of the species concerned. It is, therefore, to be hoped that the decision to form such an organisation, taken at the Zoos and Conservation Symposium at London in 1964, will soon bear fruit. The lack of such an organisation was not felt in the early stages of Operation Oryx, because the owners of almost all captive animals readily agreed to add them to the common pool, and I am sure that the authorities at Phoenix were never refused any help or advice they may have sought from their fellow zoo directors. More recently, however, an incident has occurred of the sort that an organisation of zoos and dealers would be able to prevent. An animal dealer, without reference to the Survival Service Commission or other authoritative body, acquired a pair of the remaining oryx at Riyadh Zoo (representing a seventh of the then known breeding stock in captivity) and, it is believed, subsequently offered them to any buyer at a very high price. There is nothing illegal in such an action, of course, but it cannot have been taken in the interest of the species, and can only be deplored.

\section{The Herd Builds Up Its Numbers}

Stage two of Operation Oryx, the building up of numbers in captivity, is now well under way and the species has shown itself to be as cooperative as in stage one by demonstrating that it will breed freely under captive conditions. The solitary fomale from Kuwait died without adding any progeny to the herd, but the four other females have between them produced eight calves: three born to the one captured in the desert (Edith), three to the one from the London Zoo (Caroline), and two from the older one in Riyadh. The first seven of those were all males, causing speculation as to whether it was merely a matter of 


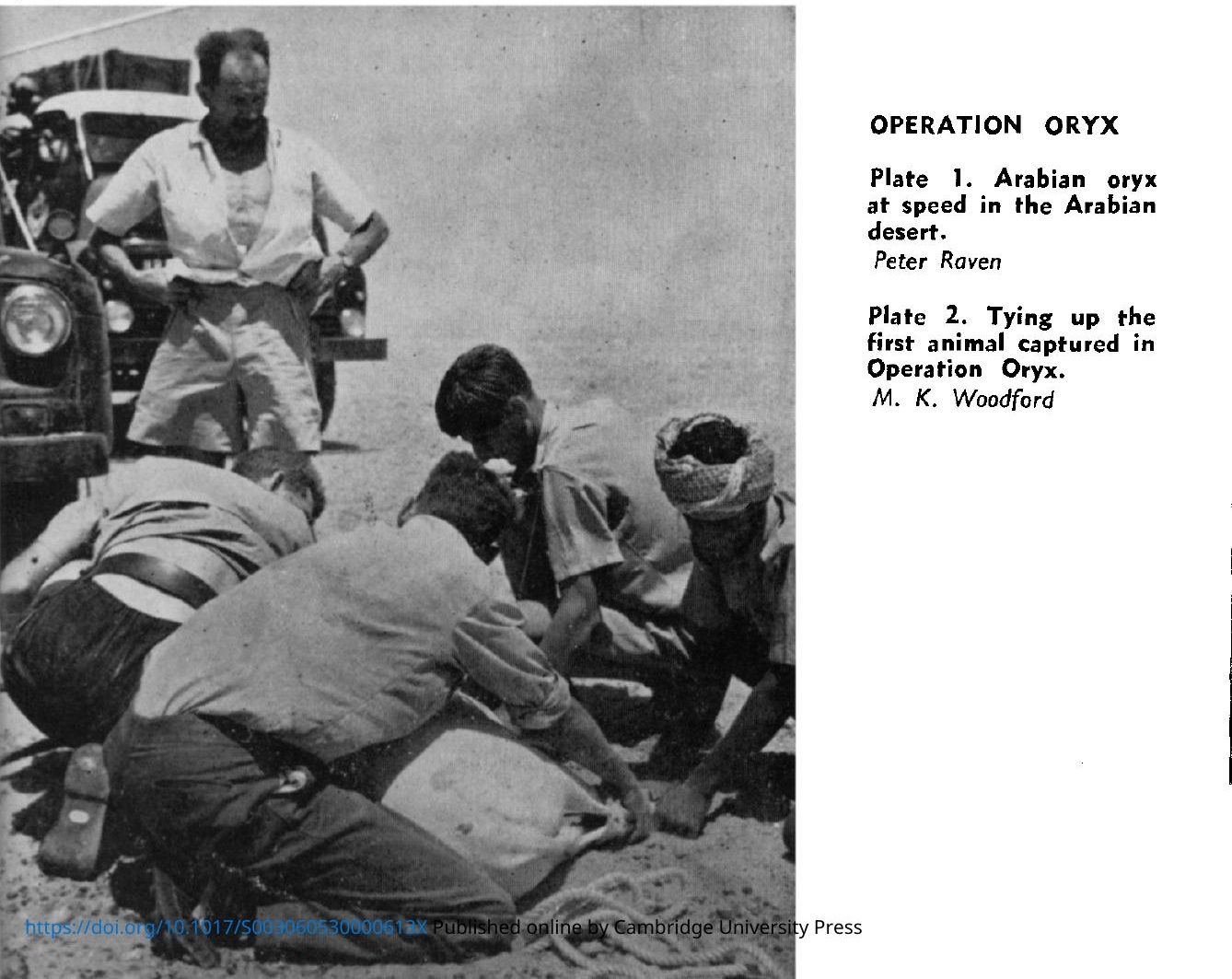




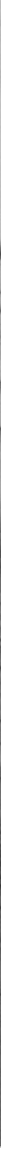

Plate 3. ORYX PENS AT PHOENIX ZOO, ARIZONA, the home of the World Herd. These pens were specially built for the animals captured in Operation Oryx. The herd now numbers 16 animals, seven of which have been born here. Arizona Zoological Society 


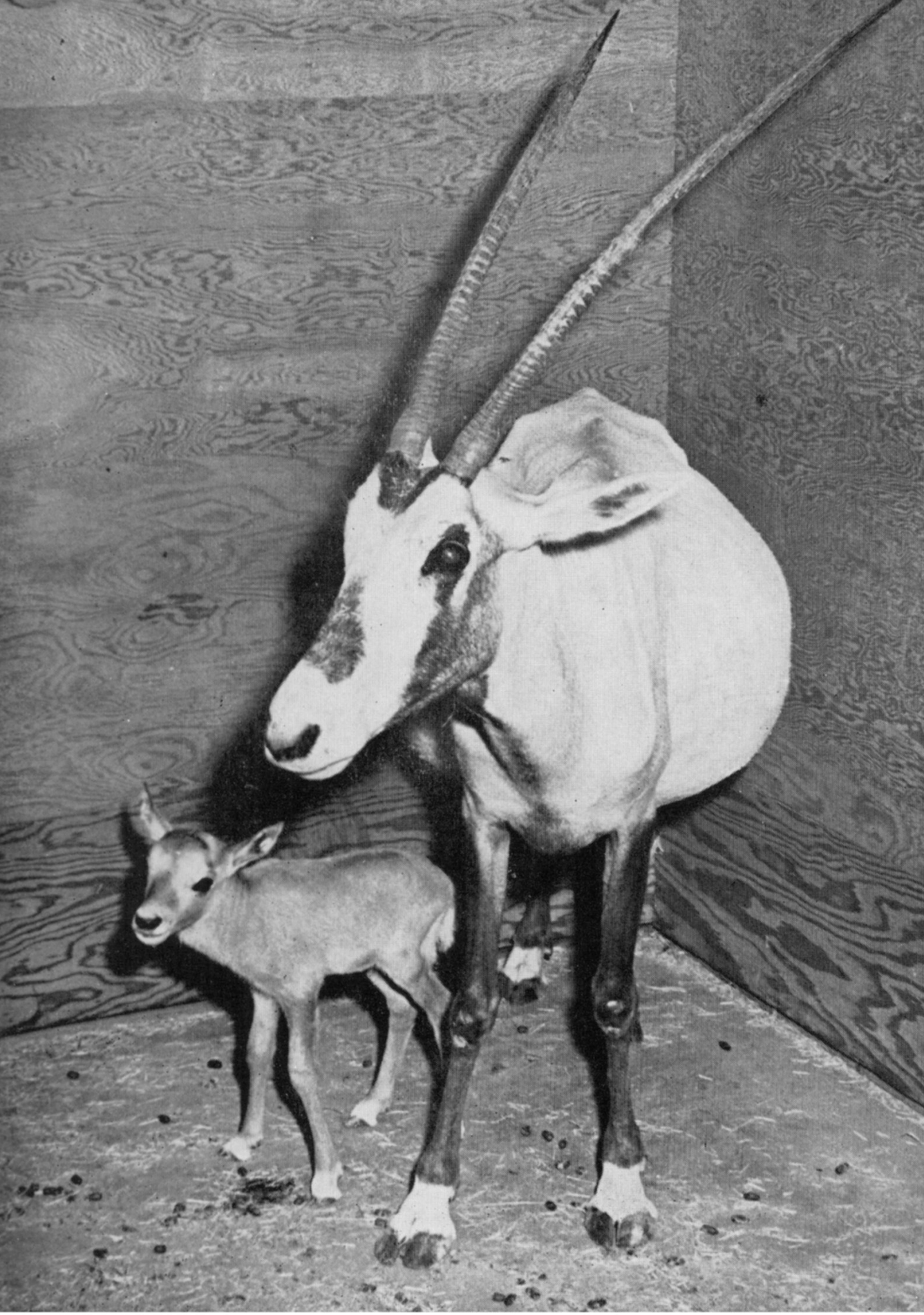

Plate 4. THE FIRST FEMALE CALF in the World Herd at

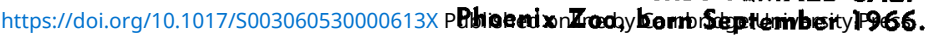




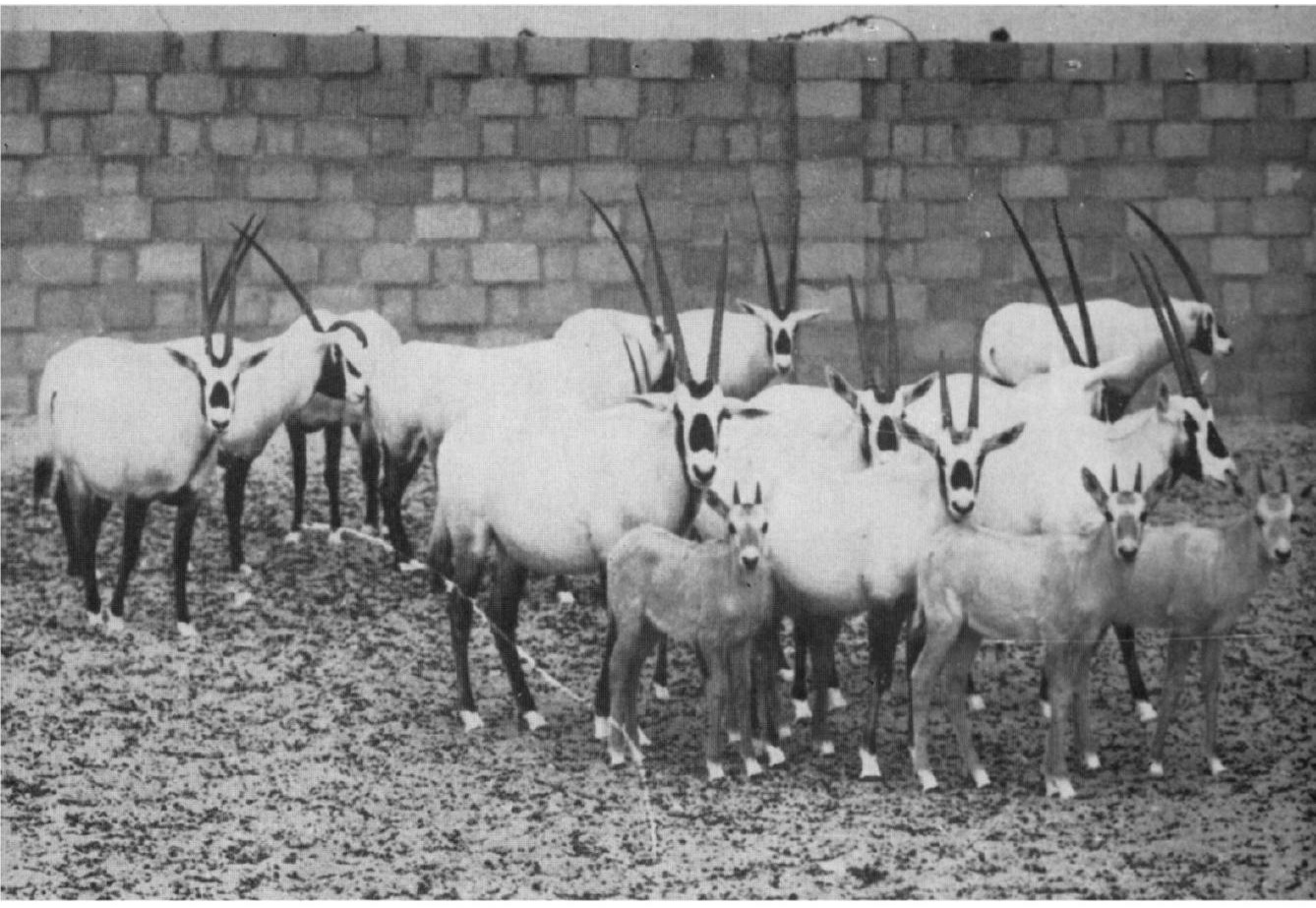

Plate 5. BREEDING HERD IN ARABIA. Part of the tine herd of Arabian oryx at the farm of HH Sheikh Qassim bin Hamad al Thani, Minister of Education of Qatar, Arabian Culf. Sheikh Qassim, who kindly sent this photograph to the FPS, has accepted the position of Chairman of the Survival Service Commission's Arabian Oryx group. The FPS keeps the stud book for the Arabian oryx. 


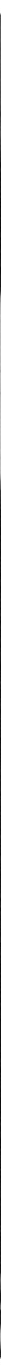

Plate 6. MOTHER AND CHILD IN PEKINC ZOO, the only zoo in the world to have bred giant pandas. World Wildlife Fund 


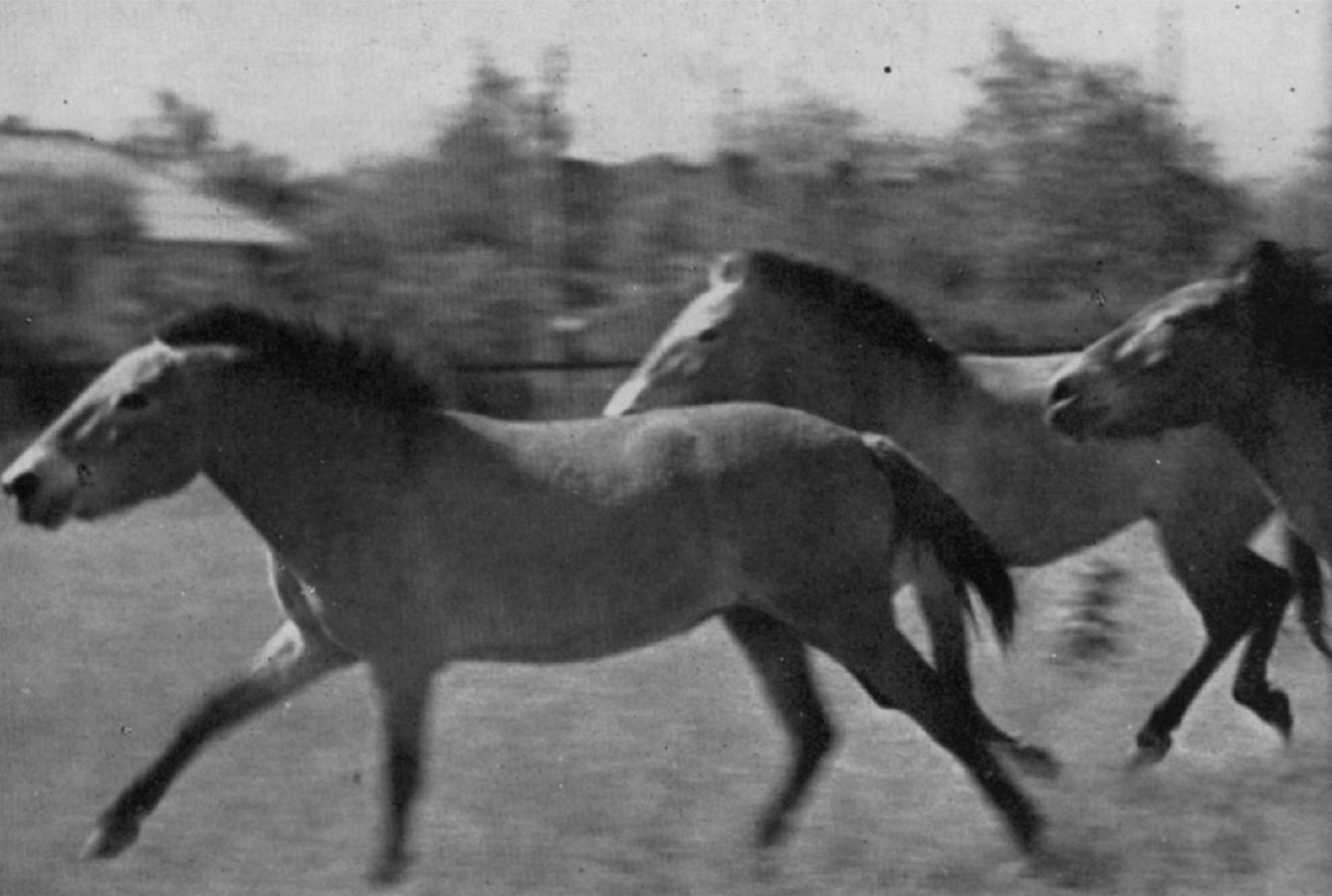

PRZEWALSKI HORSES. Plate 7 breeding herd at the AskaniyaNova Zoopark in the Ukraine. This, the only truly wild horse alive today, is almost extinct in the wild. See page 90.

Askaniya Nova Zoopark

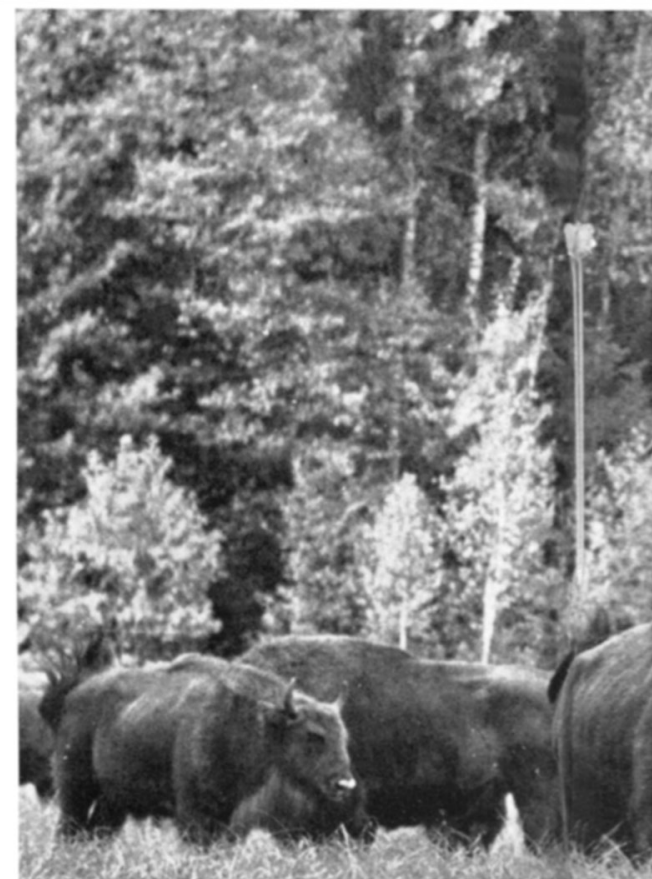



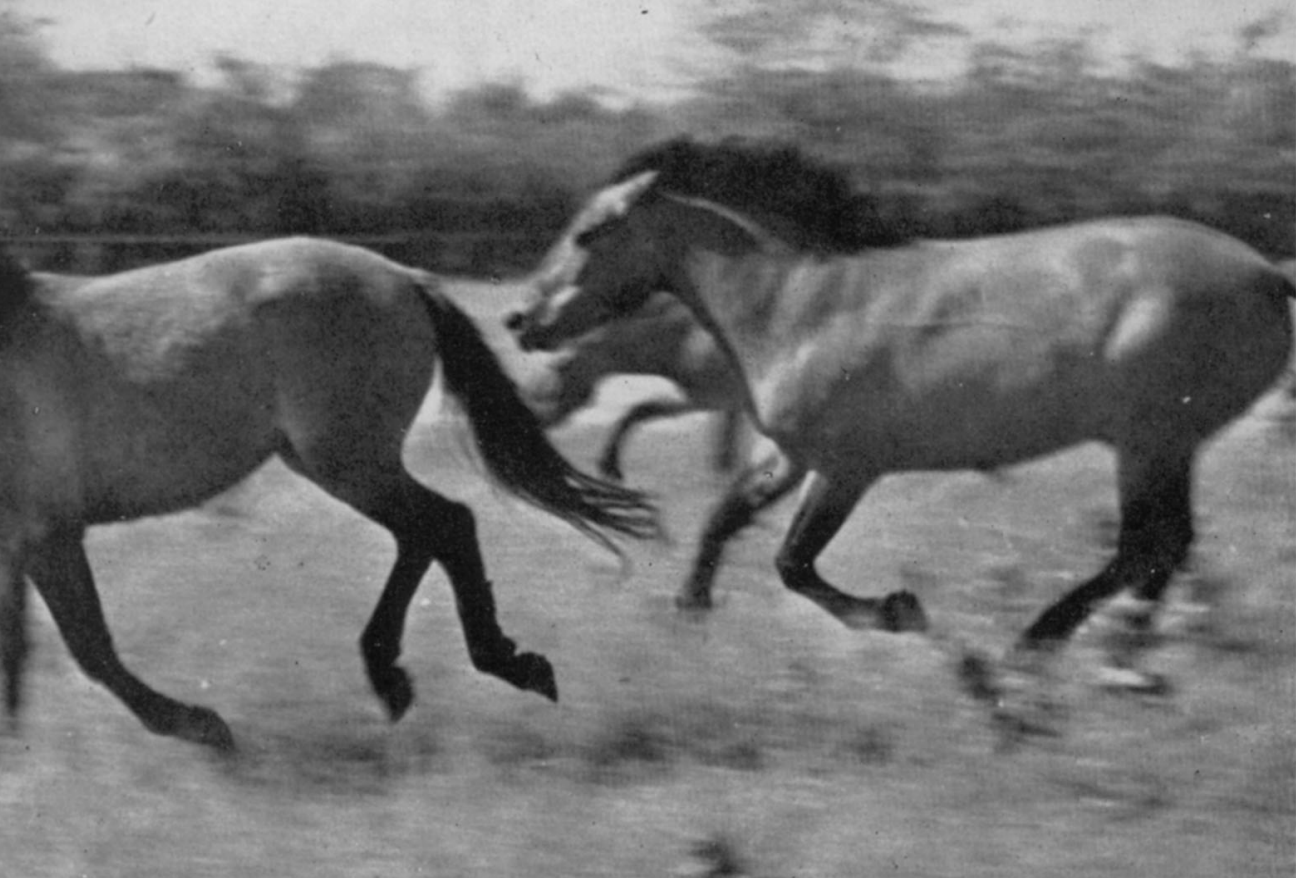

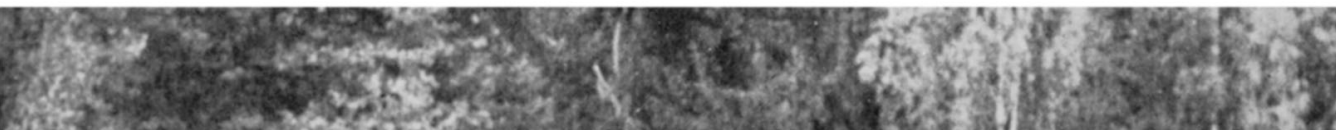
Sy

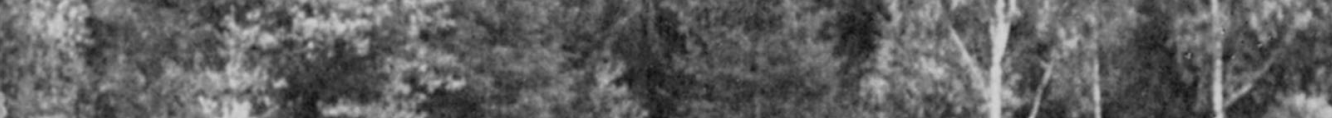

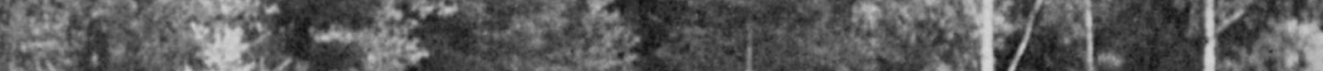

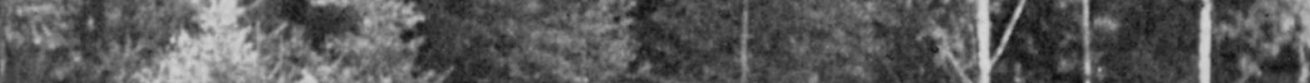
2.

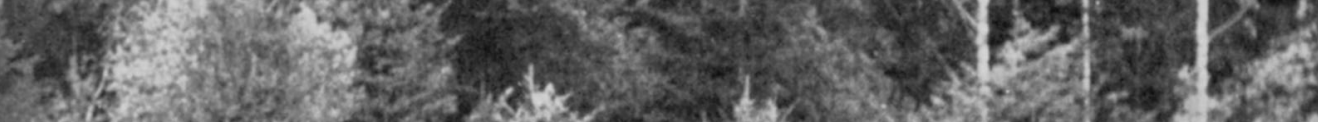

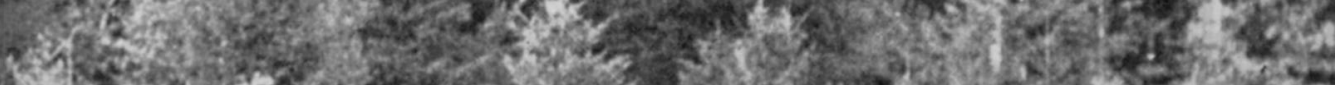

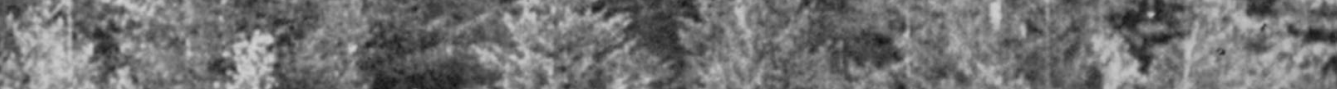

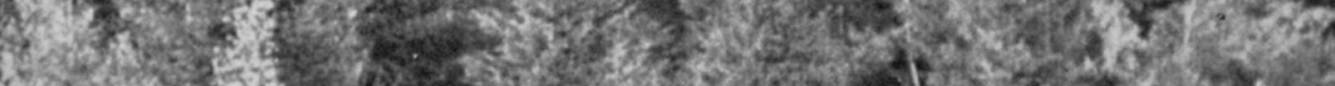

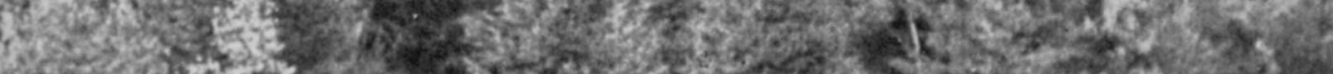

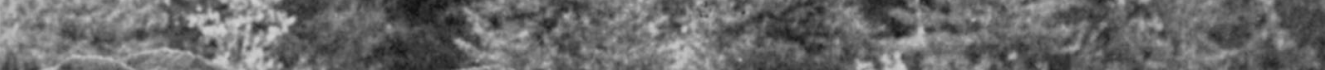

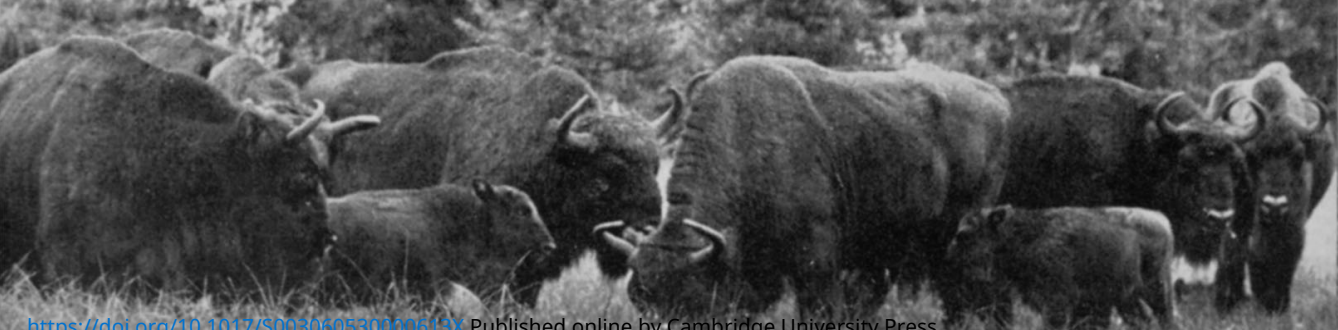

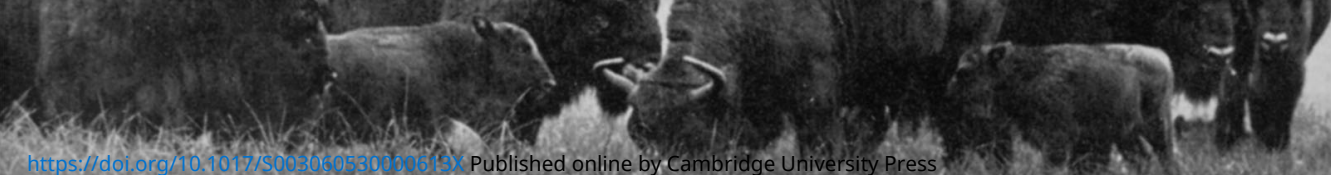




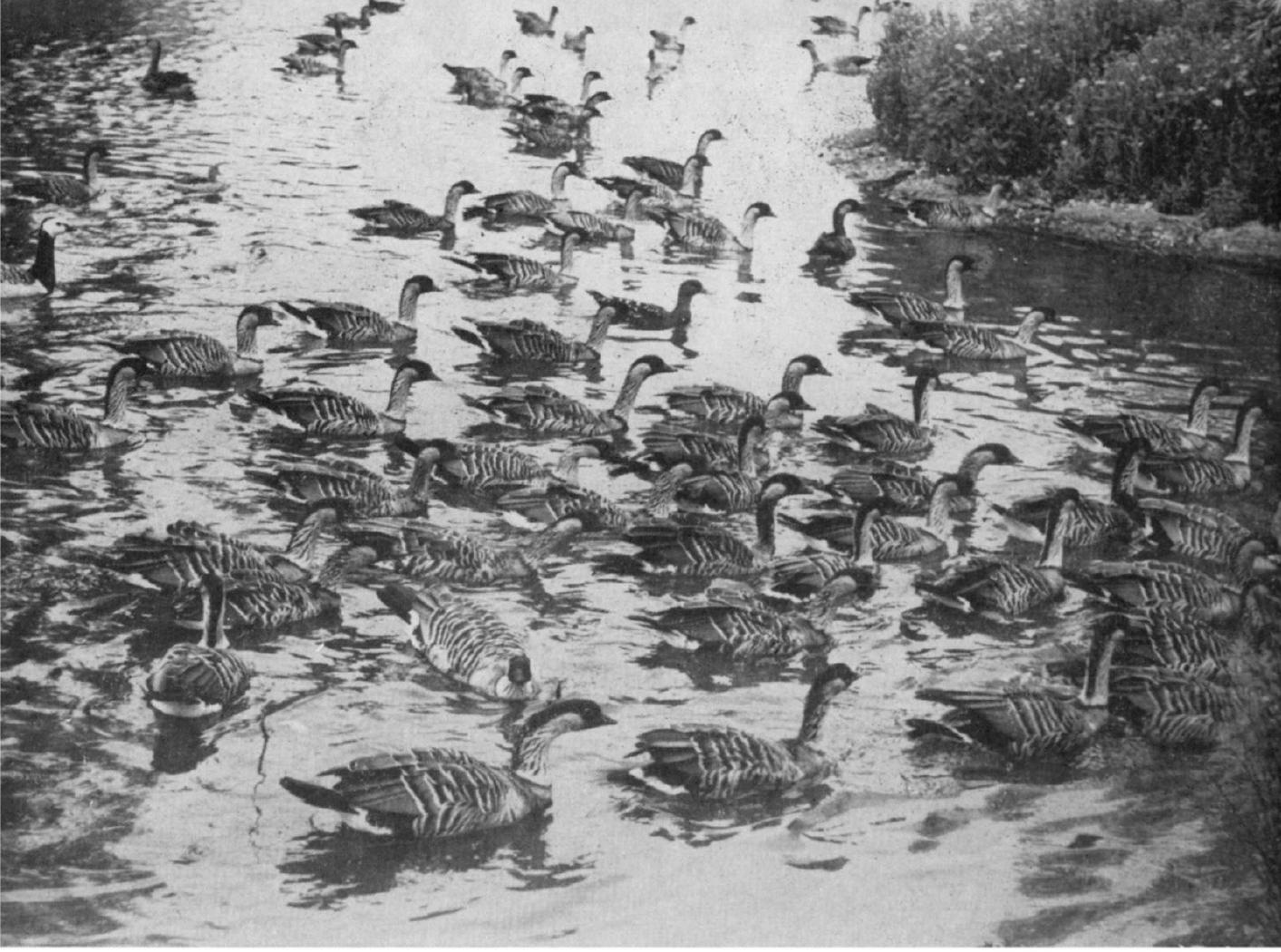

Plate 9. NE-NES BRED BY THE WILDFOWL TRUST. Some of these birds have now been flown to Hawaii, where the species was almost extinct, and released in the wild. Philippa Scott

Plate 10. PACKED FOR THE

FLIGHT. Dursley Gazette, Glos.
Plate 11. JOURNEY'S END. Ne-nes trom England released in Hawaii. IUCN

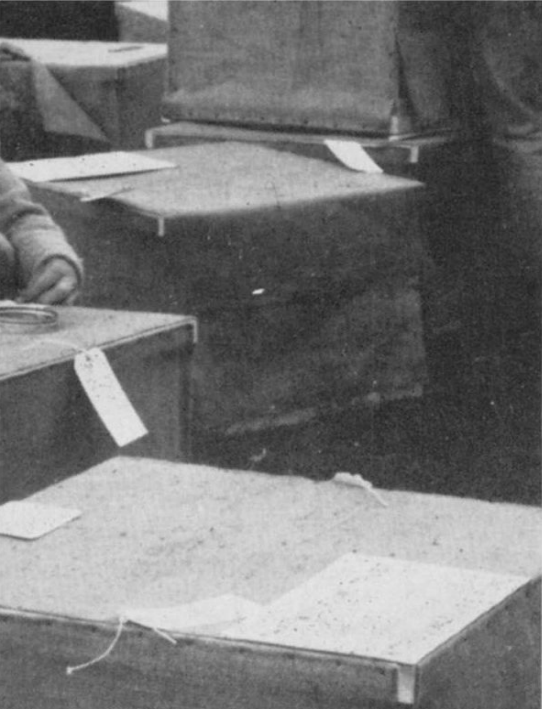



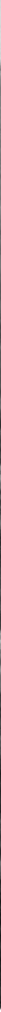

SWINHOE'S PHEASANTS RELEASED IN TAIWAN. This year Mr Philip Wayre, Director of the Ornamental Pheasant Trust in Norfolk, England, took 30 of the very rare Swinhoe's pheasants bred by the Trust, to Taiwan (Formosa) for release in the wild. Plate 12 above shows the release pen for the birds close to indigenous primary forest. The Taiwan Covernment has now given full protection to Swinhoe's pheasant. Philip Wayre

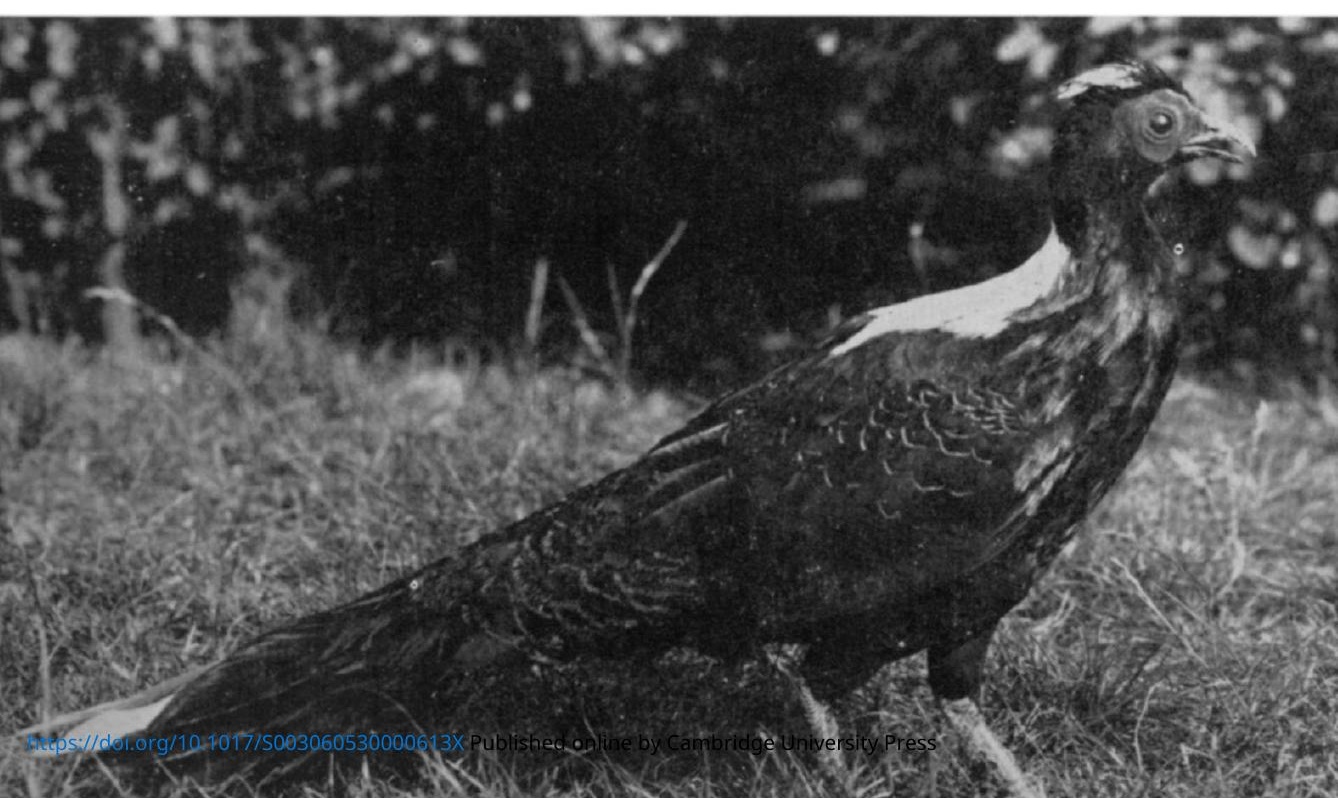


Unknown in the wild, this unique deer from China was saved by the 11th Duke of Bedford, who built up a large herd at Woburn Abbey, in Bedfordshire, from which today all the known animals in zoos and collections throughout the world are derived. See page 89 . G. Kenneth Whitehead 
IN THE NAIROBI ANIMAL ORPHANAGE

Plate 15 


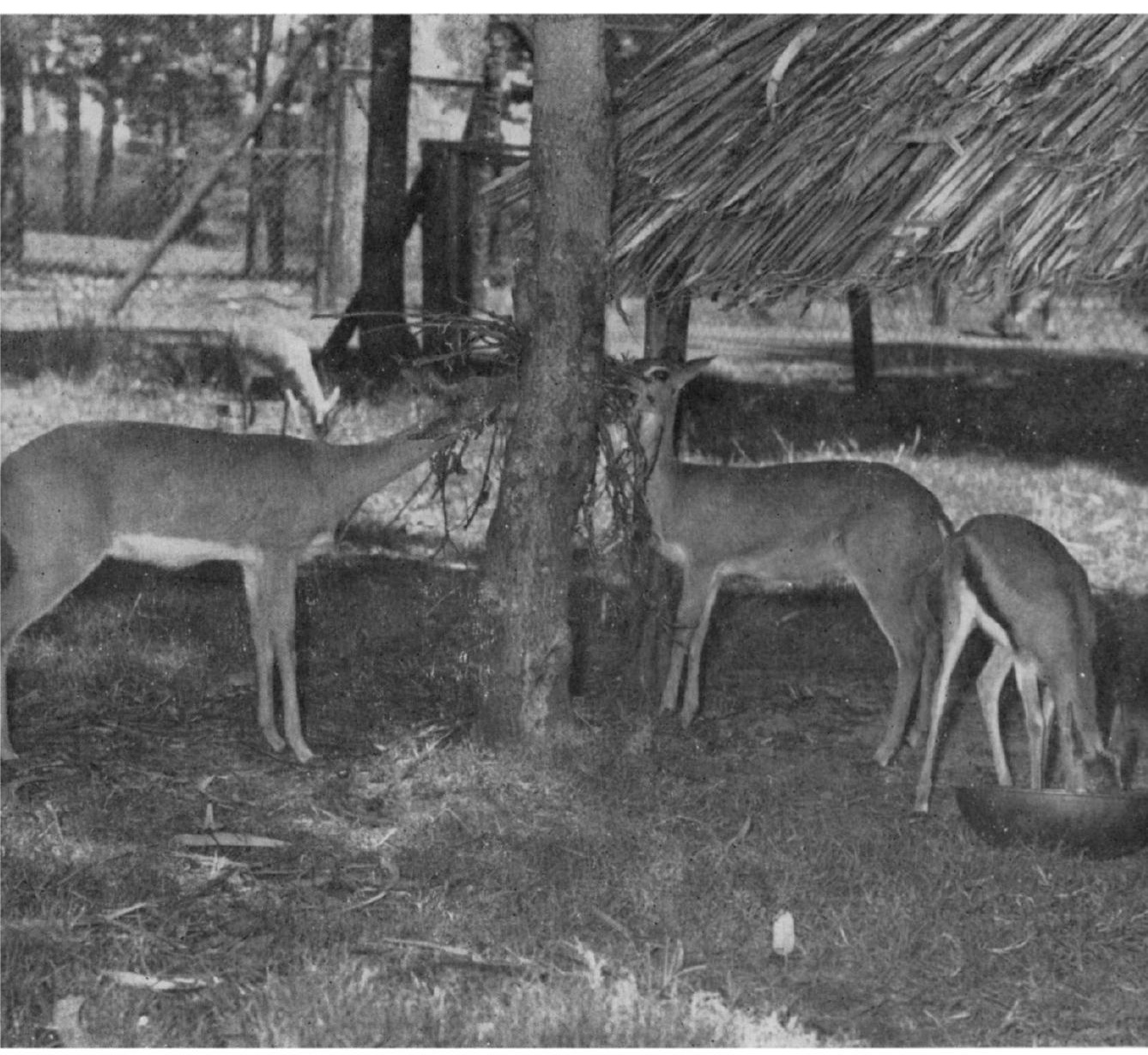

Plate 16. REEDBUCK AND A THOMSON'S GAZELLE IN THE PENS IN NAIROBI ANIMAL ORPHANAGE.

The work of the Orphanage is described by Mr Olindo, Director of National Parks in Kenya, page 101.

Plate 15 overleat. A LEOPARD CUB in the arms of Mr Cade, Curator of the Orphanage. 
mathematical chance, some form of prepotency in the two males which sired all seven, or perhaps the result of some unknown factor having to do with un-natural conditions under which the animals were living. The eighth and last calf, born on the 8th September last, and sired by a male which had not been bred from before, proved to be a female, however, and it is hoped that the run of bad luck has been broken, or the unknown problem has solved itself.* There are still only five females in the herd, however, which is a perilously small number to carry the future of the species, particularly as one of them (the one from London Zoo) is known to be at least seven years old. There is therefore no room for complacency, nor can the position be regarded as satisfactory until the number has increased at least ten-fold.

The Fauna Preservation Society is maintaining a stud book for the species, and breeding is being conducted on scientific lines. The future of the herd is controlled by a board of trustees made up of representatives of the owners of the original animals i.e. the Fauna Preservation Society, the Zoological Society of London, and the World Wildlife Fund, together with the Arizona Zoological Society and the Shikar-Safari Club. The overall plan is to establish two, or perhaps three, more captive breeding herds at other places, as an insurance against calamity, before any attempt is made to re-introduce the species into the wild.

\section{Prospects For Stage Three}

Prospects for that final stage are now much brighter than they were a few years ago, when it seemed that there was nowhere within its former range where the species could be re-introduced in safety. National parks are now in being, or in the process of being created, in the desert areas of both Jordan and Israel, and both countries have shown great interest in providing the first true refuge for the Arabian oryx. The choice of the latter country might create political problems under present circumstances, but it will be many oryx generations and therefore many years before liberation can be contemplated, by when the situation may have changed.

Thanks to the interest which has been aroused in the fate of the Arabian oryx, more information has become available on the status of the animal in its sole remaining haunt in the wild, along the southeastern edge of the Rub-al-Khali, in the state of Muscat and Oman. Various British officers of the Sultan's armed forces, and geologists prospecting on behalf of oil companies, have reported sightings of up to twenty animals at a time, and it now appears probable that some 200 animals still exist, mainly concentrated in the Jiddat-al-Harrasis region. These have been afforded a degree of protection by an order of the Sultan prohibiting the hunting of oryx from motor vehicles, but the danger of unauthorised raids from across the border still

*A second female calf was born on January 11 th, 1967. 
exists. There is also the fear that traditional Arab hospitality would make it difficult for a direct request for hunting facilities from an influential guest or neighbour to be refused. It is, however, gratifying that the local Bedouin are reported to be now well aware of the rarity of the animal and to regard themselves as trustees of it to the Sultan.

Information has also come to hand of more oryx in captivity. A female calf was caught on the Jiddat-al-Harrasis last year by an officer of the Sultan's armed forces as a mascot for his regiment, and the latest information available is that, having been made aware of the present captive breeding programme, His Highness has offered to present that calf and one other, which the same officer was authorised to capture last spring, as a contribution to the world effort. It has also been learned that Sheikh Qassim bin Hamad al Thani has a number of oryx at his home in Qatar. A member of the original capture party who visited him last year, reported his animals to consist of nine males and six females, all in good condition, with most of the females apparently pregnant.

The rescue programme for the Arabian oryx is now well into the next stage, that of building up numbers in captivity. The Arizona Zoological Society, with whom the ball now lies, have shown that they can breed oryx at Phoenix, and, at last, that they can breed female oryx too. All that remains, therefore, is for them to go into mass production. We can only wish them luck in that endeavour and hope that one day we may all attend a gathering similar to this to listen to a paper on how they succeeded, and how the Arabian oryx was successfully re-introduced into the wild.

For those interested in further details of the oryx programme up to date, the Fauna Preservation Society published a full account of the capture operation in Vol. VI No. 6 of ORYX in December, 1962, and an account of follow-up operations in Vol. VII No. 5, August, 1964. D. R. M. Stewart, the biologist who took part in that expedition, published in Vol. I of the journal of the East African Wild Life Society, August 1963, a summary of all that had previously appeared in the literature on the Arabian oryx and its biology, supplemented by his own observations and including a comprehensive list of the vegetation on which he had found it to feed. That has now been followed by Special Bulletin No. 1 of the Arizona Zoological Society, in the first part of which Jack Throp gives additional information to that published by Stewart and in the second part outlines breeding successes up to December 1964 and plans for the development of the herd. 